\title{
The Effect of Chest Computed Tomography Findings on QT Interval in Patients with COVID 19 Using Drugs That May Prolong QT Interval
}

\author{
Ferhat Özyurtlu ${ }^{1}$, Nurullah Cetin ${ }^{2}$, and Veysel Yavuz ${ }^{3}$ \\ ${ }^{1}$ special grand medical hospital \\ ${ }^{2}$ Celal Bayar Universitesi Tip Fakultesi \\ ${ }^{3}$ Akhisar Mustafa Kirazoglu State Hospital
}

April 1, 2021

\begin{abstract}
Background Some drugs used in the treatment of coronavirus disease 2019 (COVID-19) are likely to increase the risk of QT interval prolongation and related arrhythmias or death. Due to the low sensitivity of the reverse transcriptase-polymerase chain reaction (RT-PCR) test, chest computed tomography (CT) imaging is being used for COVID-19 diagnostic correlation and to evaluate whether there is pneumonic involvement in the lung. Objective In this study, we aimed to compare whether there was a difference in terms of QT interval prolongation and effect on heart rate in COVID-19 patients based on their chest CT findings and drug treatment regimes. Methods This was a single-center retrospective cohort study of non-intensive care unit (ICU) patients hospitalized. A total of 344 patients with a mean age of $46.34 \pm 17.68$ years were included in the study (56.1\% men). Patients were divided into four groups according to their chest CT results as having typical, atypical, indeterminate, or no finding of pneumonic involvement. Mean QTc intervals and heart rates calculated from electrocardiograms at admission and after treatment were compared. Results There were no significant differences between groups with regards to age, gender, and body mass index (BMI). There were also no significant differences between the groups in terms of mean QTc interval values upon admission (p:0.127) or after treatment (p:0.205). Heart rate values were similar among the groups as well, with no significant differences in mean heart rate on admission (p:0.648) and post-treatment (p:0.229) ECGs. Conclusion This study has demonstrated finding of COVID-19 infection based on chest CT does not affect QT interval prolongation and bradycardia in non-ICU COVID-19 patients. There is a need for additional larger studies investigating the effect of chest CT findings on QT interval prolongation and bradycardia in COVID-19 patients.
\end{abstract}

\section{Hosted file}

ijcp.pdf available at https://authorea.com/users/405258/articles/516264-the-effect-of-chestcomputed-tomography-findings-on-qt-interval-in-patients-with-covid-19-using-drugs-thatmay-prolong-qt-interval

\section{Hosted file}

table.pdf available at https://authorea.com/users/405258/articles/516264-the-effect-ofchest-computed-tomography-findings-on-qt-interval-in-patients-with-covid-19-using-drugsthat-may-prolong-qt-interval

\section{Hosted file}

figure.pdf available at https://authorea.com/users/405258/articles/516264-the-effect-ofchest-computed-tomography-findings-on-qt-interval-in-patients-with-covid-19-using-drugs- 
that-may-prolong-qt-interval 